\title{
Sequential Finite Element Model of Tissue Electropermeabilization
}

\author{
Davorka Šel, David Cukjati, Danute Batiuskaite, Tomaž Slivnik, Member, IEEE, Lluis M. Mir, and \\ Damijan Miklavčič**
}

\begin{abstract}
Permeabilization, when observed on a tissue level, is a dynamic process resulting from changes in membrane permeability when exposing biological cells to external electric field (E).

In this paper we present a sequential finite element model of $E$ distribution in tissue which considers local changes in tissue conductivity due to permeabilization. These changes affect the pattern of the field distribution during the high voltage pulse application.

The presented model consists of a sequence of static models (steps), which describe $\mathbf{E}$ distribution at discrete time intervals during tissue permeabilization and in this way present the dynamics of electropermeabilization. The tissue conductivity for each static model in a sequence is determined based on $\mathbf{E}$ distribution from the previous step by considering a sigmoid dependency between specific conductivity and $E$ intensity. Such a dependency was determined by parameter estimation on a set of current measurements, obtained by in vivo experiments. Another set of measurements was used for model validation. All experiments were performed on rabbit liver tissue with inserted needle electrodes. Model validation was carried out in four different ways: 1) by comparing reversibly permeabilized tissue computed by the model and the reversibly permeabilized area of tissue as obtained in the experiments; 2) by comparing the area of irreversibly permeabilized tissue computed by the model and the area where tissue necrosis was observed in experiments; 3 ) through the comparison of total current at the end of pulse and computed current in the last step of sequential electropermeabilization model; 4) by comparing total current during the first pulse and current computed in consecutive steps of a modeling sequence.

The presented permeabilization model presents the first approach of describing the course of permeabilization on tissue level. Despite some approximations (ohmic tissue behavior) the model can predict the permeabilized volume of tissue, when exposed to electrical treatment. Therefore, the most important contribution and novelty of the model is its potentiality to be used as a tool for determining parameters for effective tissue permeabilization.
\end{abstract}

Index Terms-Electrochemotherapy, electro gene transfer, electropermeabilization, modeling, validation.

Manuscript received October 15, 2003; revised October 19, 2004. This work was supported in part by the European Commission, within the 5th framework programme under Grant Cliniporator QLK3-1999-00484. Asterisk indicates corresponding author.

D. Sel, D. Cukjati, and T. Slivnik are with the University of Ljubljana, Faculty of Electrical Engineering, Tržaška 25, SI-1000 Ljubljana, Slovenia (e-mails: davorka@svarun.fe.uni-lj.si; david@lbk.fe.uni-lj.si; tomaz.slivnik@fe.uni-lj.si).

D. Batiuskaite is with Vytautas Magnus University, Department of Biology, LT-3000 Kaunas, Lithuania (e-mail: a8daba@vaidila.vdu.lt).

L. M. Mir is with UMR 8121 CNRS, Institute Gustave-Roussy, F-94805 Villejuif Cedex, France (e-mail: luismir@igr.fr).

*D. Miklavčič is with the University of Ljubljana, Faculty of Electrical Engineering, Tržaška 25, SI-1000 Ljubljana, Slovenia (e-mail: damijan@svarun.fe.uni-lj.si).

Digital Object Identifier 10.1109/TBME.2005.845212

\section{INTRODUCTION}

$\mathbf{E}$ XPOSURE of cells, either in suspension or in tissue, to the appropriate, short, intense electric pulses results in reversible change of their membrane permeability [1], [2]. Consequently the membrane becomes permeable for molecules which otherwise cannot cross cell membrane, such as proteins, some drugs and nucleic acids. This biological property of cell membrane has been already exploited for the transfer of chemotherapeutic agents into cells [3]-[7]. Corresponding therapeutic method is referred to as electrochemotherapy. In preclinical trials another application is currently taking place, where DNA is transferred into cells by means of applied external electric field [6], [8], [9]. This method is referred to as electro-gene transfer or electrogenetherapy and is facilitated either by trains of identical pulses of 20 or $50 \mathrm{~ms}$ [8], [10] or by short high voltage electric pulse, which permeabilizes cells, followed by longer low voltage electrophoretic pulse(s) that does not affect cell permeabilization level but facilitates DNA transfer into the cell [11]. Electrogenetherapy is currently gaining a lot of attention, because it is considered a safe method compared to other methods of in vivo gene transfer [12].

The transport of molecules facilitated by permeabilization occurs either during the pulse application or after it, while the cell membrane is still permeabilized. The transport of small molecules like bleomycin or cisplatin which are used in electrochemotherapy was suggested to occur mainly by diffusion process through the permeabilized membrane after the pulses [13]. For larger molecules as DNA just the membrane permeabilization is not sufficient as electrophoretic drag needs to be exerted on DNA in order to obtain sufficient transport. Therefore, shorter pulses can be used for electrochemotherapy whereas longer pulses or a combination of short high voltage and long low voltage pulses are used for electro-gene transfer [11].

Theory and experiments have shown that the extent of cell membrane permeabilization depends on electric field intensity, cell size, shape and interaction with surrounding cells [14], [15]. Several factors related to permeabilized cells such as cells volume fraction, conductivity of medium, membrane conductivity, cell orientation and critical transmembrane potential (TMP) affect effective tissue conductivity. The relationship between these factors and the effective conductivity of cells in suspension has been described previously [16]. Besides effective conductivity the key parameter of permeabilization on a tissue level is the local electric field intensity. As the field results from a voltage applied between the electrodes, the electrode configuration 
influences the field distribution in tissue [17]-[19]. Electrode configurations used for tissue permeabilization are parallel plates, wire and contact plate electrodes as well as needle electrodes and needle arrays [19]-[21].

Theory and experiments have shown that the extent of cell membrane permeabilization depends on electric field intensity, cell size, shape and interaction with surrounding cells [14], [15]. Several factors related to permeabilized cells such as cells volume fraction, conductivity of medium, membrane conductivity, cell orientation and critical transmembrane potential (TMP) affect effective tissue conductivity. The relationship between these factors and the effective conductivity of cells in suspension has been described previously [16]. Besides effective conductivity the key parameter of permeabilization on a tissue level is the local electric field intensity. As the field results from a voltage applied between the electrodes, the electrode configuration influences the field distribution in tissue [17]-[19]. Electrode configurations used for tissue permeabilization are parallel plates, wire and contact plate electrodes as well as needle electrodes and needle arrays [19]-[21].

Theory and experiments have shown that the extent of cell membrane permeabilization depends on electric field intensity, cell size, shape and interaction with surrounding cells [14], [15]. Several factors related to permeabilized cells such as cells volume fraction, conductivity of medium, membrane conductivity, cell orientation and critical transmembrane potential (TMP) affect effective tissue conductivity. The relationship between these factors and the effective conductivity of cells in suspension has been described previously [16]. Besides effective conductivity the key parameter of permeabilization on a tissue level is the local electric field intensity. As the field results from a voltage applied between the electrodes, the electrode configuration influences the field distribution in tissue [17]-[19]. Electrode configurations used for tissue permeabilization are parallel plates, wire and contact plate electrodes as well as needle electrodes and needle arrays [19]-[21].

In most applications of tissue permeabilization it is required to expose the volume of tissue to $\mathrm{E}$ intensities between the two thresholds, i.e., to choose in advance a suitable electrode configuration and pulse parameters for the effective tissue permeabilization. Therefore, electric field distribution in tissue has to be estimated before the treatment, which can be achieved by combining results of rapid tests [18], [24] with models of electric field distribution. However, modeling of electric field distribution in tissue is demanding due to heterogeneous tissue properties and usually complex geometry. Analytical models can be employed only for simple geometries. Usually they are developed for two-dimensional problems and tissue with homogenous electrical properties [25]. Therefore, in most cases numerical modeling techniques are still more acceptable as they can be used for modeling three-dimensional geometries and complex tissue properties. For that purpose mostly finite element method (FEM) and finite difference method are applied. Both numerical methods have been successfully applied and validated by comparison of computed and measured electric field distribution [17], [18], [22]. However, non of the previously reported work took into consideration also tissue conductivity increase due to tissue or cell permeabilization.

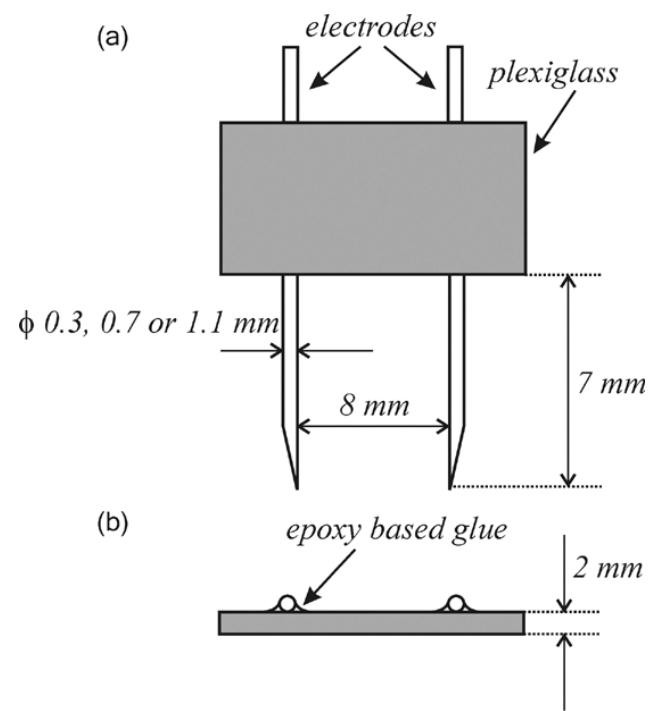

Fig. 1. Needle electrodes used in experiments: (a) side view; (b) top view.

In this paper, we present the first model which describes tissue permeabilization by taking into account tissue conductivity change. The model consists of a sequence of static models (steps), which describe $\mathrm{E}$ distribution in discrete time intervals during permeabilization. In this way model presents dynamics of electropermeabilization since in each step the tissue conductivity is changed according to distribution of electric field intensities from the previous step. For that purpose tissue conductivity in the model is expressed as a function of electric field intensity. Sigmoid dependency between specific conductivity and electric field intensity is used. Estimation of the sigmoid function parameters is based on current measurements. Namely current indicates the extent of permeabilization [26], [27] through the change in the tissue conductivity [28], [29], [46]. The proposed model of tissue electropermeabilization is then validated on experimentally obtained total current measurements and areas of reversibly and irreversibly permeabilized rabbit liver tissue.

\section{MATERIALS AND MethodS}

\section{A. Experiments}

In vivo experiments were performed at the Institute GustaveRoussy, France on rabbit liver tissue in accordance with European Commission Directives and French legislation concerning animal welfare. Three rabbits were used in the experiments. Animals were kept anaesthetised for the whole duration of the experiments. A subxypoid incision was made and the liver was gently exteriorised and exposed to electrical treatment. For that purpose two parallel needle electrodes as shown in Fig. 1 were inserted perpendicularly to tissue surface approximately $7 \mathrm{~mm}$ in depth. In experiments three different needle diameters were used: $\phi=$ $0.3 \mathrm{~mm}, \phi=0.7 \mathrm{~mm}$ and $\phi=1.1 \mathrm{~mm}$. The inner distance between the needles was always $8 \mathrm{~mm}$ as in [22]. Eight rectangular monophasic pulses of $100 \mu \mathrm{s}$ duration and $1 \mathrm{~Hz}$ repetition frequency were applied. Pulses were delivered by pulse generator Jouan GHT 1287B, St.Herblain, France. Applied pulse amplitudes were in the range of $200 \mathrm{~V}-1200 \mathrm{~V}$. The applied voltage and resulting current were acquired by high voltage and current probes 
respectively and stored on-line by digital oscilloscope (LT344, LeCroy Corporation, USA). Altogether 13 experiments were performed with needles of diameter $0.3 \mathrm{~mm}, 13$ experiments with needles of $1.1 \mathrm{~mm}$ diameter, whereas 41 experiments were performed with $0.7 \mathrm{~mm}$ diameter needles. These experiments were performed in the same way as in our previous work [22], with the difference that in previous experiments reversibly and irreversibly permeabilized areas of tissue were determined, while the current was not measured. In present experiments total current was measured. Therefore, the results of both experiment sets were used in present study for the purpose of the model parameter estimation and model validation.

\section{B. Sequential Model of Permeabilization Around Two Needle Electrodes}

Basic idea behind sequential permeabilization model is that when a short high voltage pulse is applied to a tissue with two needle electrodes inserted, the E distribution in the tissue is dependent on the local conductivity. In addition the $\mathrm{E}$ distribution, provided higher than permeabilizing value, causes changes in local conductivity. This makes tissue permeabilization a dynamic process.

We assumed in the model that change in local tissue conductivity $(\sigma)$ caused by $\mathrm{E}$ intensity has characteristic profile, i.e., $\sigma(E)$ dependency, which is specific for each type of the tissue. When the constant voltage is applied by inserting needle electrodes to tissue with homogeneous conductivity for example, the resultant $\mathrm{E}$ distribution in tissue is inhomogeneous. According to $\sigma(E)$ dependency and as a result of the tissue exposure to inhomogeneous $\mathrm{E}$ distribution, the tissue conductivity becomes heterogeneous. Namely in the volume of tissue exposed to E intensity above reversible threshold the tissue conductivity increases, while in the rest of the tissue the conductivity remains unchanged.

E distribution in tissue with increased conductivity due to permeabilization differs from the distribution in completely nonpermeabilized tissue. Namely, E intensities are higher in part of still nonpermeabilized tissue comparing to previous distribution of $\mathrm{E}$ intensities. Consequently, increased $\mathrm{E}$ intensities cause $\sigma(E)$ dependant conductivity change. The process continues in this manner until the increased $\mathrm{E}$ intensity in part of nonpermeabilized tissue is lower than reversible threshold. The process of tissue permeabilization is then terminated.

Following this idea a sequence of static finite element models was designed in order to describe electropermeabilization process at discrete time intervals. In each static model (step) the tissue conductivity is determined based on the electric field distribution and specific conductivity from the previous step in the sequence, as described in (1)

$\sigma(k, x, y, z)=f(E(k-1, x, y, z), \sigma(k-1, x, y, z))$, for $k \geq 2$

where $\mathrm{E}$ denotes electric field intensity, $\sigma$ denotes tissue conductivity, $k$ the step in the modeling sequence and $x, y, z$ spatial coordinates. In (1) $\sigma(k, x, y, z)$ is different from $\sigma(k-1, x, y, z)$ only if the field $E(k-1, x, y, z)$ is larger than the permeabilizing value. Conductivity in the first step $(k=1)$ was approximated as homogenous.

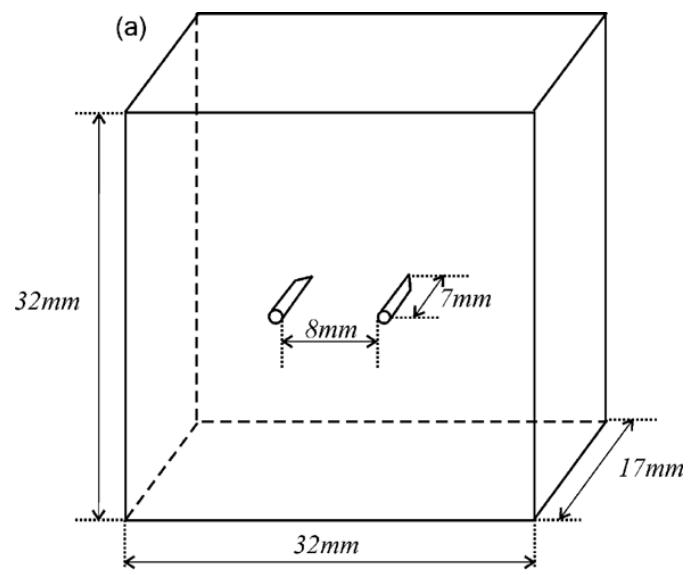

(b)

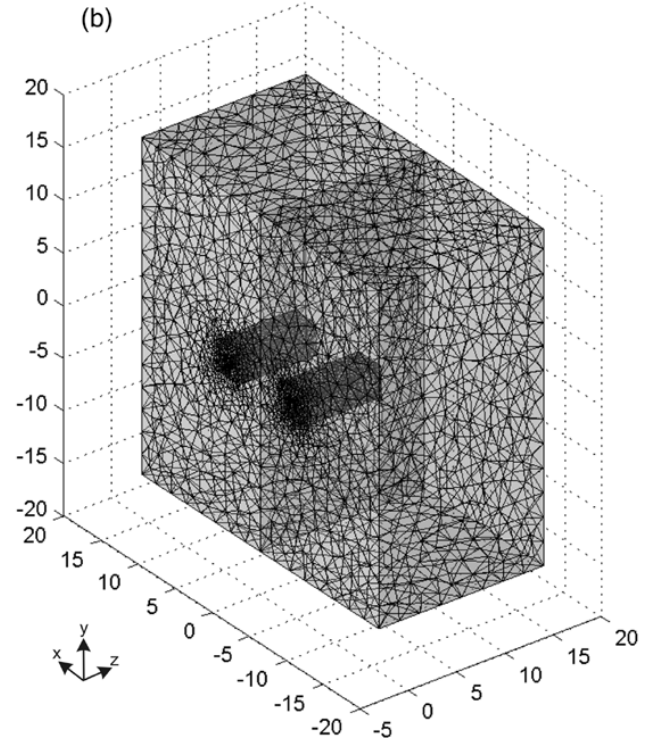

Fig. 2. (a) Geometry under study and (b) finite element mesh for the model with needles of $0.7-\mathrm{mm}$ diameter.

\section{Finite Element Model}

A three dimensional FE model of a liver tissue with inserted needle electrodes was designed using software package Femlab v2.3 produced by Comsol, Sweden. The geometry under the study and the resultant finite element mesh are shown in Fig. 2. The needle electrodes were modeled as 8 faceted shapes instead of cylinders, which we found, in our previous work, to give proper results and at the same time spent less computing power [30]. Due to the fact that needles were significantly smaller than surrounding tissue, finite element mesh was designed to be much denser in regions around electrodes than at the edge of the parallelepiped. The mesh, for example of model with needle diameter $0.7 \mathrm{~mm}$ consisted of 7697 nodes, 728 edge elements, 6627 boundary elements and 38997 elements.

Electric field distribution was described by means of equations for steady electric current in volume conductor, due to the fact that constant voltage was applied during the pulses to tissue, approximated as isotropic material with ohmic behavior. Steady electric current in volume conductor was described by means of Laplace equation. Laplace equation together with two types of boundary conditions, i.e., Dirichlet and Neumann boundary conditions, describes electric field inside the volume conductor. The Dirichlet boundary condition, defined as a fixed scalar electric potential 
(constant voltage), was applied to the surface of the electrodes. Neumann boundary condition, defined as the first derivative of the scalar electric potential in the normal direction to the surface, was automatically set to zero on the outer border of the model.

The model simulation was run on personal computer (Intel Pentium III, $1 \mathrm{GHz}$ CPU, 265 MB RAM) with Windows XP operating systems. The time spent on solving one model (step) in a sequence was 12 minutes.

\section{RESUlTS AND DISCUSSION}

\section{A. Parameter Estimation}

Under our experimental condition (sampling rate was 25 $\mathrm{MS} / \mathrm{s}$ ), no significant delay between voltage and current was observed and also negligible transient response was detected with respect to the pulse length, which was the reason to use ohmic approximation of the tissue in the model. For the illustration the voltage and the current during the first pulse are presented in Fig. 11 in Appendix I.

Parameter estimation of $\sigma(E)$ dependency was carried out on a subset of experiments with current measurements. For each needle electrode diameter we selected measurements at three different voltages, i.e., around the reversible threshold, above the irreversible threshold and in the middle of the two thresholds. Threshold voltages were chosen according to previously published values for rabbit liver tissue in [22]. The conductivity of nonpermeabilized tissue $\left(\sigma_{0}\right)$ was computed from our experiments at low voltages, far below the reversible threshold. Computed value for rabbit liver $\left(\sigma_{0}=0.067 \mathrm{~S} / \mathrm{m}\right)$ was smaller than the mean values for human liver tissue reported in the literature [31]-[34]. However in [32], the lack in agreement between the measurements in low frequency region and at body temperature is reported for the liver conductivities of other mammals-the range of rabbit liver conductivity in [32] was between 0.027 and $0.091 \mathrm{~S} / \mathrm{m}$ and even wider range was presented for guinea pig. The value of non permeabilized rabbit liver conductivity obtained in our experiments is well within that range.

The $\sigma(E)$ dependency was fitted by a sigmoid function

$$
\sigma(E)=\frac{\sigma_{1}-\sigma_{0}}{1+D e^{-\frac{E-A}{B}}}+\sigma_{0}
$$

where $\sigma_{1}$ denotes maximal conductivity of permeabilized tissue and $D$ is sigmoid function parameter. Parameters $A$ and $B$ depend on reversible $\mathrm{E}$ threshold value $\left(E_{0}\right)$ and irreversible $\mathrm{E}$ threshold value $\left(E_{1}\right)$, and are, therefore, expressed as

$$
\begin{aligned}
& A=\frac{E_{0}+E_{1}}{2} \\
& B=\frac{E_{1}-E_{0}}{C}
\end{aligned}
$$

where $C$ is the sigmoid function parameter.

Electropermeabilization tissue parameters subject to estimation were, thus, $E_{0}, E_{1}, \sigma_{1}$ and sigmoid function parameters $C$ and $D$. Parameters were estimated by optimizing modeled current to be close to the measured current, obtained in experiments. We used current measurement for parameter estimation as in [28] it was suggested that current can be used for measuring in vivo the change in conductance due to permeabilization and

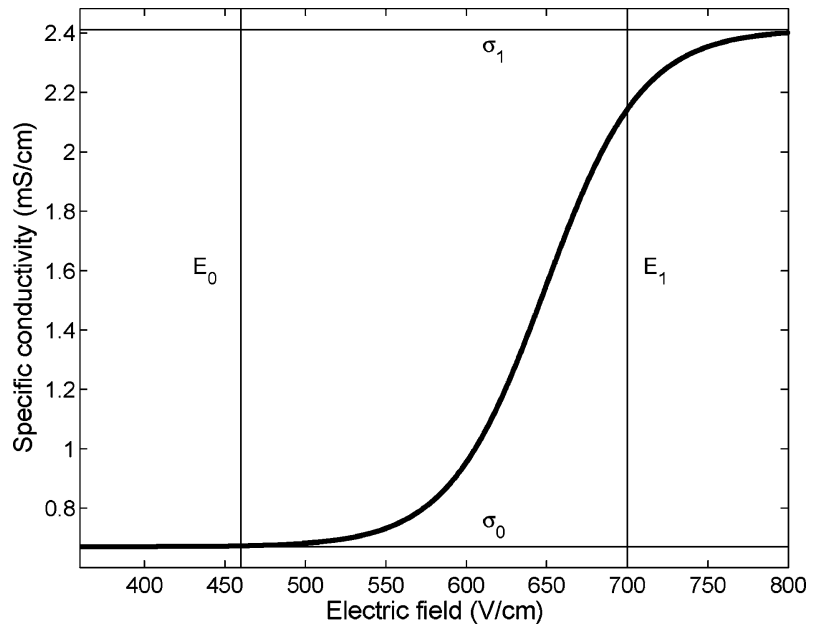

Fig. 3. Optimized conductivity dependency on electric field $\sigma(\mathrm{E})$.

TABLE I

COMPARISON OF MODElled AND MEASURED CURRENT AT THREE DifFERENT VOLTAGES FOR NEEDLE DIAMETERS $0.3,0.7$, AND $1.1 \mathrm{~mm}$

\begin{tabular}{crccc}
\hline \hline$\phi(\mathrm{mm})$ & $\mathrm{Up}(\mathrm{V})$ & Measured I (A) & Modeled I (A) & Rel. error (\%) \\
\hline 0.3 & 617 & 0.58 & 0.62 & -7 \\
\hline 0.3 & 815 & 0.90 & 0.92 & -3 \\
\hline 0.3 & 1023 & 1.11 & 1.23 & -11 \\
\hline 0.7 & 507 & 0.54 & 0.55 & -1 \\
\hline 0.7 & 704 & 0.87 & 0.90 & -3 \\
\hline 0.7 & 909 & 1.20 & 1.28 & -7 \\
\hline 1.1 & 508 & 0.49 & 0.60 & -23 \\
\hline 1.1 & 707 & 1.04 & 1.02 & 2 \\
\hline 1.1 & 911 & 1.46 & 1.43 & 2 \\
\hline \hline
\end{tabular}

also as the extent of membrane permeabilization in pellets in [26] was determined by current measurements.

Estimated parameter values were $E_{0}=460 \mathrm{~V} / \mathrm{cm}, E_{1}=$ $700 \mathrm{~V} / \mathrm{cm}, \sigma_{1}=0.241 \mathrm{~S} / \mathrm{m}, C=8$ and $D=10$. Fig. 3 presents $\sigma(E)$ dependency based on these estimated parameters. Comparison of measured and modeled current is presented in Table I.

The reason for choosing the sigmoid function to describe $\sigma(E)$ dependency was that by considering differences in cell size, shape and their interaction we can expect some cells to be permeabilized before the others when $\mathrm{E}$ above $E_{0}$ is applied. That was also observed in [22], where at reversible E threshold normal and altered nuclei (by bleomycin) were found next to each other in the middle region between electrodes, which could result in gradual increase in the tissue conductivity at $E_{0}$ described by $\sigma(E)$ curve. By increasing $\mathrm{E}$ above $E_{1}$ the loss of viability of some cells occurs and latter of all cells which again leads into gradual saturation of $\sigma(E)$ curve. Similarly Teissie $e t$ al. [35], described the influence of cell size on electropermeabilization. They stated that the population of permeabilized cells increases with an increase in field strength.

In general, for use in the permeabilization model $\sigma(E)$ dependency should be determined for each subjected type of tissue. The simplest approach toward determination of $\sigma(E)$ dependency would be by controlled set of experiments where electrical treatment is performed with plate electrodes. In such a way the parameters $E_{0}, E_{1}, \sigma_{0}, \sigma_{1}$ could be computed directly from measurements and only parameters $\mathrm{C}$ and $\mathrm{D}$ estimated. The use of plate electrodes is however limited by the shape of tissue and 
electrode set up available. It should be also mentioned that the surface of the tissue in contact with plate electrodes is difficult to estimate, thus, the usage of plate electrodes may bring larger measurement error than the needle electrodes.

The presented model is developed to describe permeabilization only when short high-voltage permeabilizing pulses are applied. It assumes that conductivity changes as soon as the field intensity exceeds reversible threshold. However, when longer pulses are applied, the conductivity may depend on the pulse duration. That is however outside the scope of the present work, which is concerned on application of short high-voltage pulses only.

\section{B. Sequential Permeabilization Model Validation}

The sequential permeabilization model with its sigmoid $\sigma(E)$ dependency was validated in the presence of an inhomogeneous E distribution. Validation was based on in vivo experiments described in Materials and Methods section.

The observed outputs of each step in sequential model, which represented values at discrete time intervals of electropermeabilization, were electric field distribution and total current. During simulations it was ascertained that under the experimental conditions used (applied voltages, number and pulse duration), a five step sequence sufficed to describe electropermeabilization process, which in other words mean that no change in conductivity was obtained with further steps.

1) Validation of the E Intensity Obtained in the Last Step of Modeling Sequence on the Area of Reversibly Permeabilized Tissue: The area of reversibly permeabilized tissue was determined by means of bleomycin method in experiments on rabbit liver tissue. Experiment description and the details of the method are given in [22]. Experiments with needle diameter 0.7 $\mathrm{mm}$ revealed that when increasing voltages were applied to the needles, at $527 \pm 30 \mathrm{~V}$ the nuclei started to become altered in the middle region between the two electrode insertions, which reflected the permeabilization of cell membrane in that part. Therefore, we run simulations of sequential permeabilization model at $520 \mathrm{~V}$ in order to compare computed E distribution with experimental results. Fig. 4 presents E distribution in five consecutive steps computed by the model. Fig. 4(a) shows E intensity in nonpermeabilized tissue, while Fig. 4(e) shows E intensity at the end of permeabilization process. During the permeabilization, as shown from Fig. 4(b) and (c), intensity of $E$ exceeded reversible threshold value in the whole area between electrodes; even more in some parts it exceeded also irreversible threshold value. However, at the end of permeabilization process modeled $\mathrm{E}$ distribution corresponds to the situation as it was observed in experiments. During the pulse application $\mathrm{E}$ intensity caused the change in membrane permeability which allowed for transfer of ions-current carriers. Consequently tissue conductivity increased, which however did not bring the same increase in membrane permeability for molecules such as bleomycin. Molecule transport namely occurs predominantly after the pulse [13]. Increase in tissue conductivity caused modification in $\mathrm{E}$ distribution, which consequently caused another change in tissue conductivity and propagation of permeabilization. That was a dynamic process, during which $\mathrm{E}$ intensity was changing very fast in the region between and around electrodes. Consequently we (a)

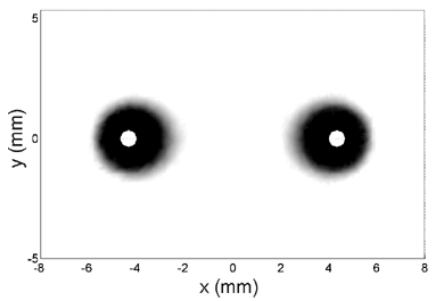

(c)

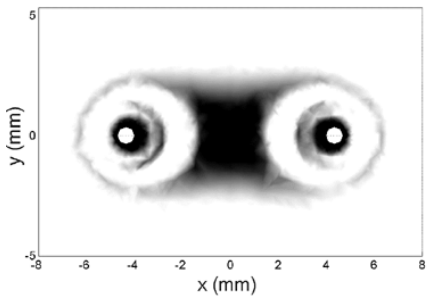

(e)

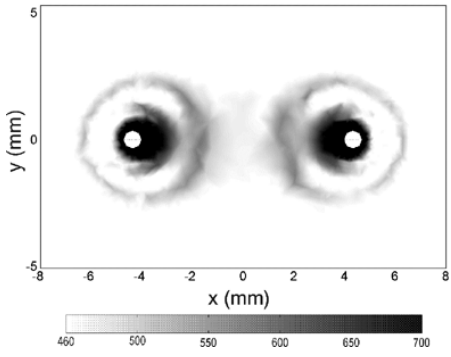

Fig. 4. Electric field during electropermeabilization as obtained in five steps of sequential electropermeabilization model: (a) first step; (b) second step; (c) third step; (d) fourth step; (e) fifth step; and (f) total current at each step. Needle diameter was $\phi=0.7 \mathrm{~mm}$. Voltage applied was $520 \mathrm{~V}$.

presume that $\mathrm{E}$ intensity above irreversible threshold value did not persist in the region between electrodes long enough to cause irreversible changes in cell membranes. We can also observe this in Fig. 7(b), where the current computed in each step of permeabilization model was compared to the current measured during the first pulse. At $500 \mathrm{~V}$ the first three steps of sequential permeabilization model occurred in less than a half of the pulse length. In that first half $\mathrm{E}$ intensity and the current were continuously changing. After the third step in the sequence the E intensity stabilized and consequently the current. We presume that steady $\mathrm{E}$ intensities influence the appearance of long lived stable pores that enable the transfer of molecules such as bleomycin after the pulse by diffusion. According to that we compared the E distribution of the fifth step in the sequence (end of permeabilization propagation) to the reversibly permeabilized area obtained in experiments. In Fig. 4(e) we can observe that in the middle between the electrodes the E intensity is just around the reversible threshold $E_{0}$, which is in accordance with experimental results.

2) Validation of E Intensity Obtained in the Last Step of Modeling Sequence on the Area of Irreversibly Permeabilized Tissue: In our previous work [22] experiments were performed on rabbit liver tissue with needle electrodes in order to determine the area of tissue necrosis at different pulse amplitudes. In Fig. 5 white line presents contour of tissue necrosis, determined during those experiments. The contour is compared to E intensity computed in the last step of electropermeabilization model (steady state) in which E, if above irreversible threshold, was 

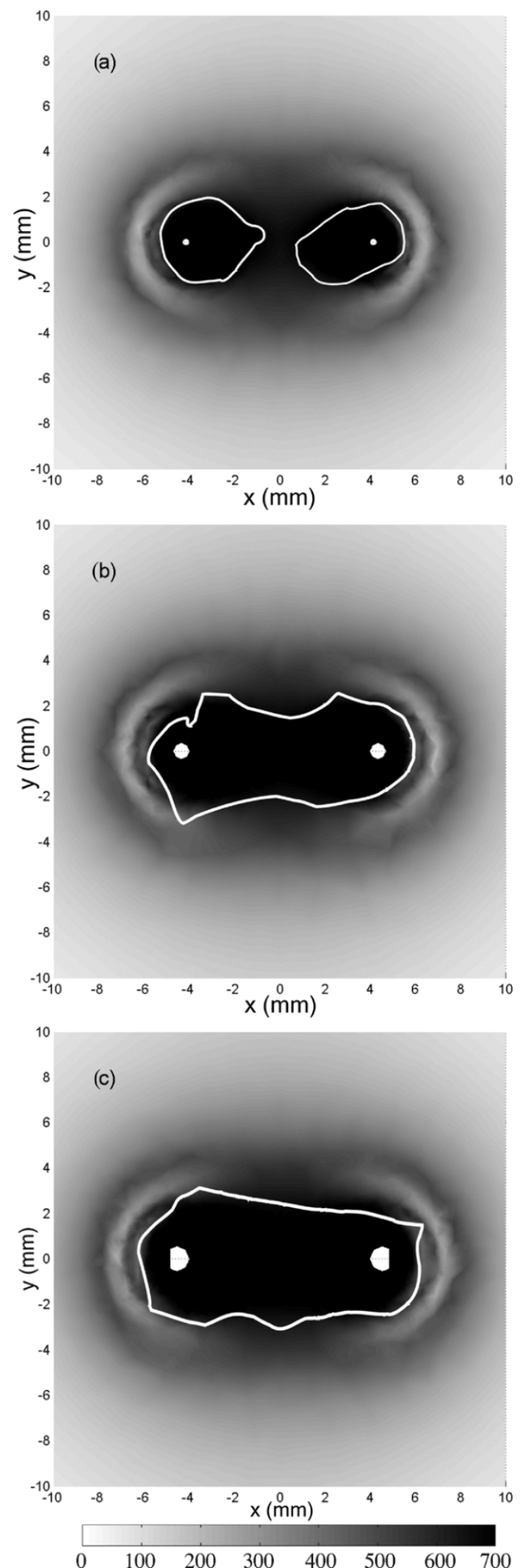

Fig. 5. Comparison of irreversibly permeabilized tissue computed by model (black area) and area of tissue necrosis determined in experiments (white contour). Needle diameter and applied voltage were: (a) $\phi=0.3 \mathrm{~mm}$, $\mathrm{U}=960 \mathrm{~V}$; (b) $\phi=0.7 \mathrm{~mm}, \mathrm{U}=960 \mathrm{~V}$; and (c) $\phi=1.1 \mathrm{~mm}$, $\mathrm{U}=952 \mathrm{~V}$.

present long enough to cause tissue necrosis. Thus, in Fig. 5 black color presents the modeled area of tissue exposed to $\mathrm{E}$
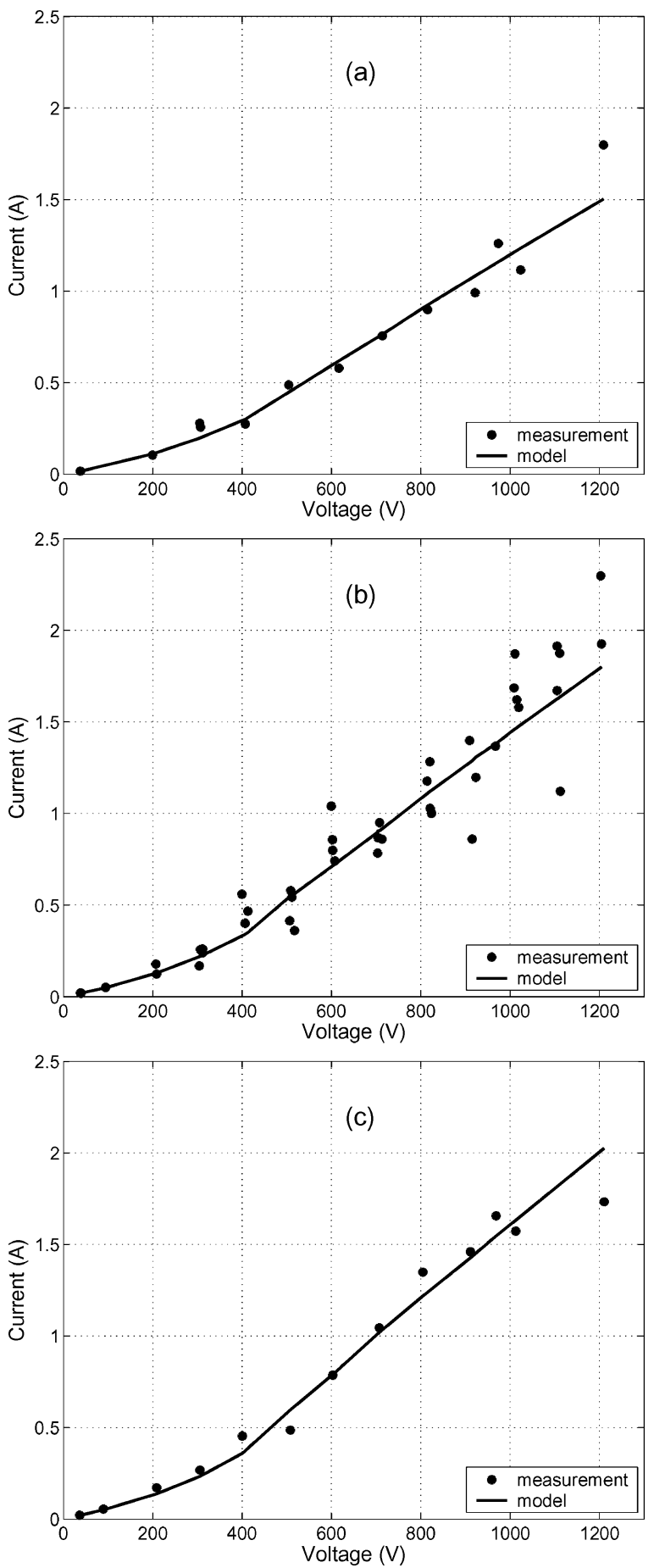

Fig. 6. Total current at the end of pulse. Comparison of computed (full line) and measured current $(*)$ at different voltages for needles with diameter (a) $\phi=0.3 \mathrm{~mm}, \mathrm{RMSE}=0.102, \mathrm{TIC}=0.061 ;$ (b) $\phi=0.7 \mathrm{~mm}, \mathrm{RMSE}=$ $0.186, \mathrm{TIC}=0.088 ;$ and $(\mathrm{c}) \phi=1.1 \mathrm{~mm}, \mathrm{RMSE}=0.105, \mathrm{TIC}=0.049$.

above irreversible threshold $\left(E_{1}=700 \mathrm{~V} / \mathrm{cm}\right)$ which matches very well the necrosis contours obtained in experiments.

3) Validation of the Current Obtained in the Last Step of Modeling Sequence on Total Current at the End of the Pulse: Total current obtained in the fifth step of the electropermeabilization model and the measured current at the end of the first pulse in rabbit liver tissue are compared in Fig. 6 for needle diameters $\phi=0.3 \mathrm{~mm}, \phi=0.7 \mathrm{~mm}$ and $\phi=1.1 \mathrm{~mm}$. In Fig. 6 also the root mean squared error (RMSE) and Theil's 
inequality criteria (TIC) measures are given, which illustrate the agreement between modeled and measured current. TIC measure for current is expressed as

$$
\mathrm{TIC}=\frac{\sqrt{\sum_{i}\left(I_{i}-I_{m i}\right)^{2}}}{\sqrt{\sum_{i} I_{i}^{2}}+\sqrt{\sum_{i} I_{m i}^{2}}}
$$

where $I$ denotes measured current and $I_{m}$ modeled current. Values of TIC are in the range between 0 and 1, where values below 0.3 indicate good agreement [37]. Considering that and based on the results presented in Fig. 6, where TIC values for needle $0.3,0.7$, and $1.1 \mathrm{~mm}$ were $0.061,0.088$, and 0.049 respectively, excellent agreement between the model and measurements was obtained.

4) Validation of Current Obtained in All Steps of Modeling Sequence on Time Course of Total Current During the First Pulse: The total currents for each of five sequential steps of electropermeabilization model at different voltages for all needle diameters and measured current response obtained during the first pulse are shown in Fig. 7. The discrete time intervals, at which the model results are presented, were determined by fitting the kinetics of the model to the measurements and by assuming independency of time intervals on pulse amplitude. The comparison shown in Fig. 7 is a preliminary. With additional measurements, for example by fitting the results with measurements obtained at 30,50 , and $70 \mu$ s duration pulses, the time steps could be defined more accurately.

Comparisons of measurements showed nonlinear increase in current when different voltages are applied, which was significant for all needle diameters. In principle, an increase in current which is not proportional to the increase in voltage reflects the increase in tissue conductivity. It was observed that the model also followed this increase in current, for all needle diameters.

We further observed (Fig. 7) that at low voltages, below permeabilization threshold, the current remained constant after the pulse rise time. This was also predicted by our model. However, at higher voltages, above reversible threshold, the current increased during the whole pulse length, while modeled current increase was only moderate. The difference could result from tissue heating and consequent increase in tissue conductivity [38]. Another reason for increased tissue conductivity could also be nonlinear increase in conductivity due to ions loosing their atmosphere (ionic and hydrational) which can occur in very high electric fields. Both effects could have occurred in tissue but were not incorporated in the model. Thus, the comparison of model current results with the current dynamics of the first pulse is a preliminary result. Further investigations have to be carried out in order to determine $\sigma(E, T)$ dependency.

Results of sequential permeabilization model, presenting permeabilization at discrete time intervals were compared only to the first pulse of current measurements. Namely, the first pulse had similar time course like the others in the train of pulses, as shown in Fig. 8(b), where applied pulse amplitude was $700 \mathrm{~V}$ [Fig. 8(a)]. In Fig. 7(b) we can observe that at $700 \mathrm{~V}$ in non permeabilized tissue (circle symbol at $t=0.2 \mu \mathrm{s}$ ) the current response would be $0.35 \mathrm{~A}$. However the current at the end of pulse was $0.82 \mathrm{~A}$, which was a result of increased conductivity due to
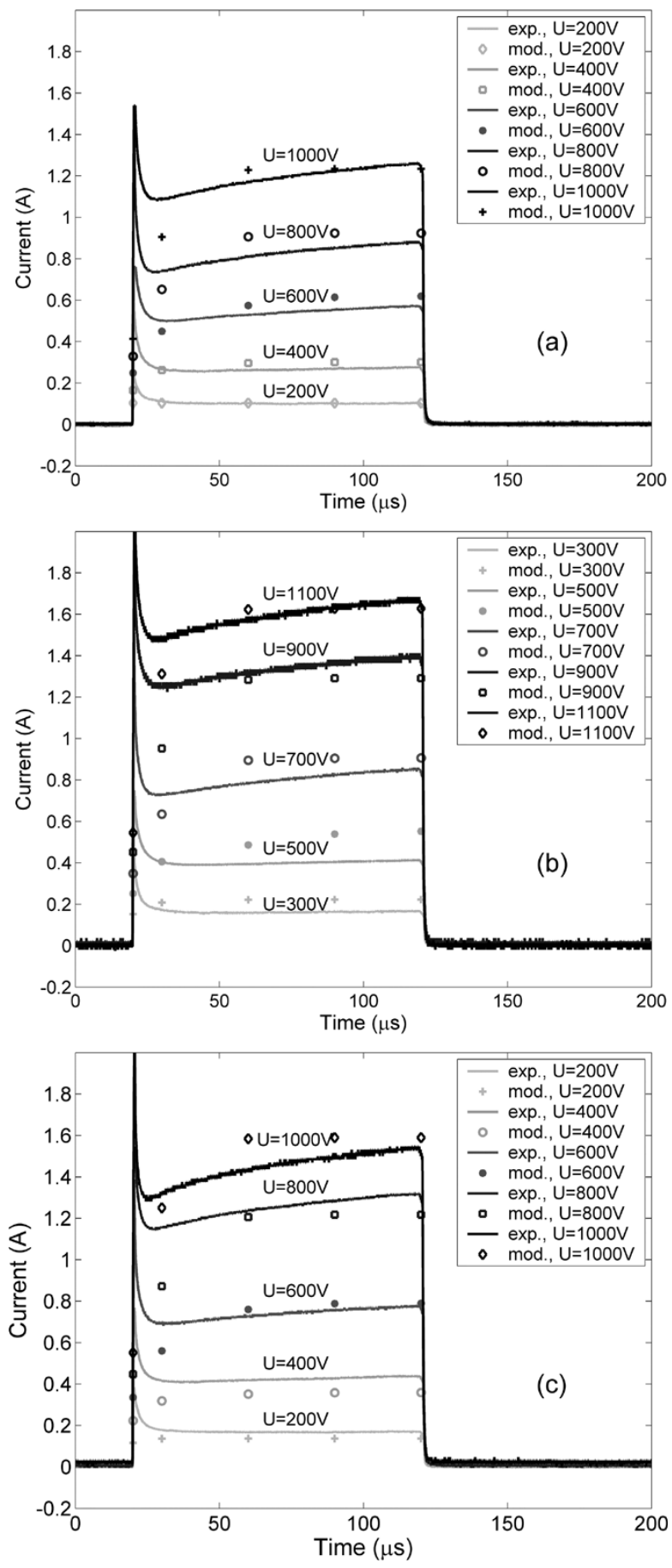

Fig. 7. Measured current during the first pulse (full line) and computed current for five sequential steps of electropermeabilization model (open symbols) at different applied voltages (expressed as parameter) and needles with diameter (a) $\phi=0.3 \mathrm{~mm}$, (b) $\phi=0.7 \mathrm{~mm}$, and (c) $\phi=1.1 \mathrm{~mm}$.

tissue permeabilization (the same was predicted by the model). That is an evidence of tissue permeabilization already during the first pulse. As current responses had similar shape when following pulses were applied we presume that during pauses between the pulses tissue resealed, at least concerning the small pores that contribute to current conductance [27], [39]. Note that in Fig. 8 the pauses between pulses ( $1 \mathrm{~s}$ ) were skipped, by employing segmentation feature of the oscilloscope which enabled the acquisitions of pulses only. 

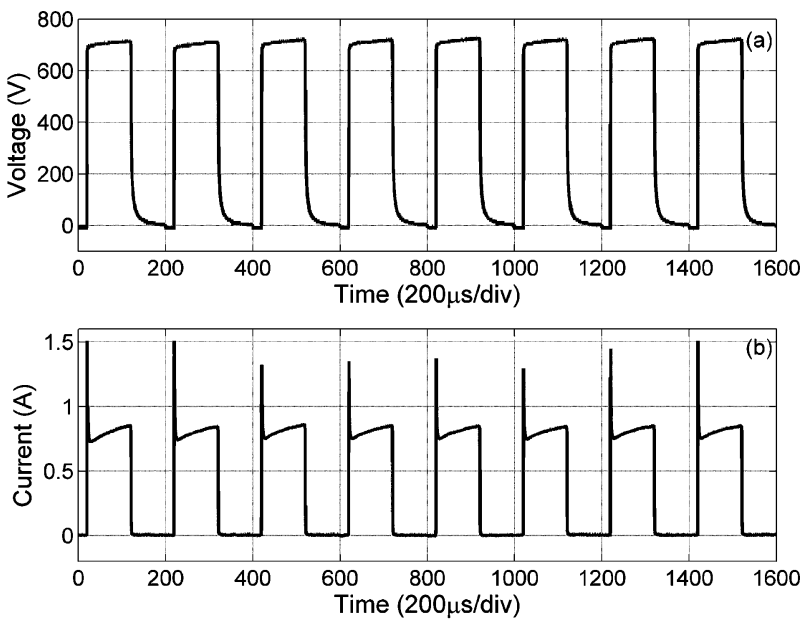

Fig. 8. Train of 8 pulses. (a) Applied voltage and (b) resulting current. Needle diameter was $0.7 \mathrm{~mm}$. Pulses were acquired using segmentation feature of the oscilloscope, which enabled to skip one second pauses between pulses.

According to one of the commonly accepted theories of cell electropermeabilization [1], [2] which explains electropermeabilization by formation of large number of metastable pores and reduced number of stable long lived pores, the metastable pores (provided already hydrophilic pores) could be responsible for increased current conduction during the pulse application. While the small number of stable pores does not contribute significant part in current conduction, however they enable the transfer of molecules after the end of the pulse by diffusion. After the end of the pulse application metastable pores reseal in the time range of microseconds [26], [27] (fast resealing). Therefore, the situation concerning current conductance is repeated after the first pulse. When several pulses are applied more stable long-lived pores are formed with cooperative effect [36], [40]. Those pores reseal in the second stage of membrane resealing which can take even up to few minutes [26], [27] and is temperature dependent active process.

Another explanation could be based on the model of pore formation energy [2], [26]. In the presence of electric field the free energy of pore formation is lower than after the pulse application. This means, that pulse reduces the free pore energy, therefore easing pore formation and consequently current flow. After the pulse application the pore radii decreases and free energy is increased. Such a situation needs to be overcome with the following pulse, which results in similar current response as in the first pulse. Both explanations however are speculative at this state of knowledge.

5) Comparison With Previously Published E Threshold Values: Permeabilization threshold values as obtained in Parameter estimation part $\left(E_{0}=460 \mathrm{~V} / \mathrm{cm}, E_{1}=700 \mathrm{~V} / \mathrm{cm}\right)$ differ from previously published values from our group $\left(E_{0}=362 \mathrm{~V} / \mathrm{cm}, E_{1}=637 \mathrm{~V} / \mathrm{cm}\right)$. The reason being that previous permeabilization thresholds were determined based on $\mathrm{E}$ distribution in nonpermeabilized tissue. Fig. 9 explains the influence of $\mathrm{E}$ distribution on threshold determination. The explanation is based on geometry consisting of two concentric cylindrical electrodes. Such geometry was chosen because it allows for the analytical description. The analytical model is given in Appendix II. Full black line in Fig. 9

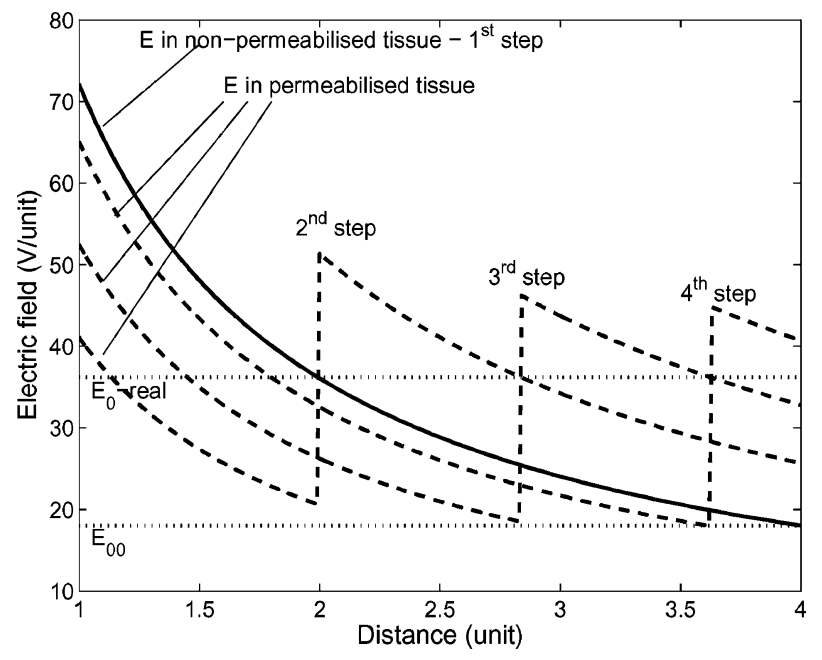

Fig. 9. Electric field distribution during electropermeabilization computed by the model, comparing to E distribution in nonpermeabilized tissue for the geometry consisting of two concentric cylindrical electrodes.

presents $\mathrm{E}$ distribution in nonpermeabilized tissue as a function of distance between electrodes. $E_{0}-$ real denotes real $\mathrm{E}$ threshold value. Dashed lines present $\mathrm{E}$ distribution computed by analytical sequential permeabilization model in steps two to four. In the first step the $\mathrm{E}$ distribution is equal to distribution in nonpermeabilized tissue. Considering $\mathrm{E}$ distribution in the first step, the permeabilization occurs in tissue up to distance 2 units (where full black line crosses dotted line denoted as $E_{0}-$ real). The tissue conductivity in that part is then increased and used in the model to calculate E intensity in the second step. The calculation considered boundary condition on E component, normal to the interface of two materials with different conductivities, which resulted in an increase of $\mathrm{E}$ intensities in nonpermeabilized tissue (dashed line which denotes second step). In the same way E distribution for steps three and four was computed. In step five, tissue along the whole distance indicated on $\mathrm{x}$ axis is permeabilized, because $\mathrm{E}$ intensity exceeded threshold value in the whole area. Once the whole area is permeabilized it has homogenous conductivity and $\mathrm{E}$ distribution becomes equal to $\mathrm{E}$ distribution of nonpermeabilized tissue. If reversible E threshold was defined on such final state, it would be the same as denoted by $\mathrm{E}_{00}$ on graph, despite the fact that true threshold value is $\mathrm{E}_{0}$ - real. The difference between $\mathrm{E}_{0}$ - real and $\mathrm{E}_{00}$ explains why the thresholds obtained by our sequential model are higher from the previously published thresholds [22].

Taking into account that molecules, which differ in size, shape and in electrical properties use different transport mechanisms (diffusion, electroosmosis, electrophoresis, etc.) [13] to cross permeabilized cell membrane, different transfer rate coefficients and time courses, can be related to their transport. The dependence of transport of ions and small molecules on applied external electric field is schematically shown in Fig. 10. According to that, the reversible threshold presented in this paper reflects the threshold for ion conduction and possibly small molecules which enter the cell by diffusion. The transport kinetics of larger molecules is more complicated and it occurs 


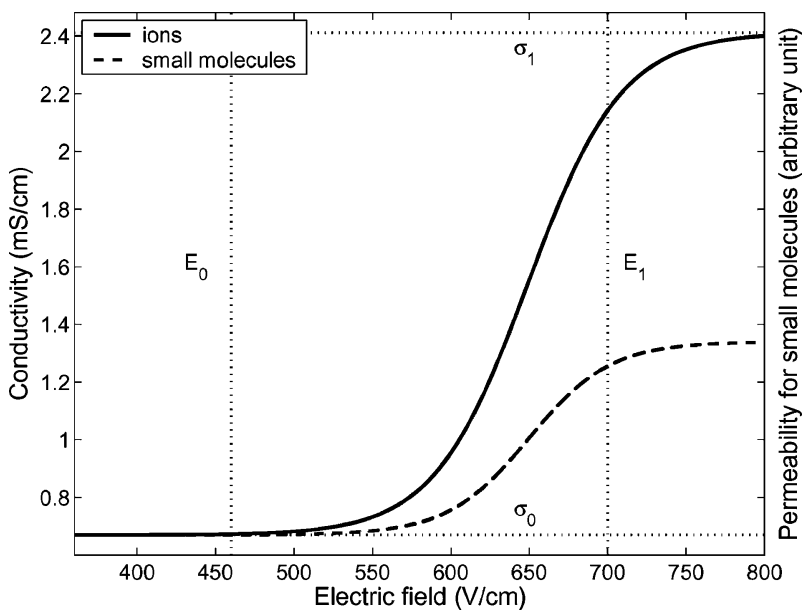

Fig. 10. Hypothetical presentation of the transport of ions and small molecules due to tissue permeabilization by applied electric field.

in several temporally distinct stages [1], [41]. It also appears that transport of larger molecules requires either long-lived stable pores or according to [36] it requires critical pore density for DNA translocation through permeabilized membrane patches following cooperative scheme. Considering the fact that membrane permeabilization for ions is fast, it causes rapid changes in $\mathrm{E}$ intensities across the tissue and consequently the propagation of permeabilization. After this process is terminated the steady distribution of $\mathrm{E}$ intensities is present for longer period of pulse duration. We presume that steady E intensities influence the appearance of long lived stable pores that enable the transfer of molecules such as bleomycin which takes place predominantly after the pulse by diffusion. Steady E intensities could be also responsible for the state of membrane permeabilization which enables the transport of larger molecules across the cell membrane by electrophoresis. Besides that the steady E intensity can be used for assessment of $E$ thresholds related to permanent cell membrane damage, such as irreversible E threshold value $700 \mathrm{~V} / \mathrm{cm}$, at which cell necrosis was observed.

6) Computed Induced Critical Transmembrane Potential From New E Thresholds: When exposing cells to external electric field the transmembrane potential (TMP) is induced. At critical TMP value $\left(\mathrm{TMP}_{\mathrm{c}}\right)$ cell membrane permeabilization occurs. Reported values of $\mathrm{TMP}_{\mathrm{c}}$ at room temperature are between 0.2 to $1 \mathrm{~V}$ [27], [42], [43]. The relation between external electric field and TMP for spherical cell is expressed by Schwan's equation: TMP $=f R E \cos \vartheta$, where $R$ is a cell diameter, $f$ numerical factor and $\vartheta$ angle between cell radius vector and $E$ vector. By taking into account the average diameter of hepatocytes being $21.8 \pm 2.7 \mu \mathrm{m}$ and by using the value of factor $f=1$ which corresponds to densely packed cells-such as in tissue [44], [45], we computed the value of $\mathrm{TMP}_{\mathrm{c}}$. Considering E threshold values $E_{0}=460 \mathrm{~V} / \mathrm{cm}$ and $E_{1}=700 \mathrm{~V} / \mathrm{cm}$, we obtained $\mathrm{TMP}_{\mathrm{c}}=0.50 \mathrm{~V}$ and TMP for irreversible threshold equal to $0.76 \mathrm{~V}$. As expected computed TMPc is slightly higher than our previously published value [22], however it is well in the range of reported values in literature.

\section{CONCLUSION}

In the present work sequential permeabilization model was developed and validated. This is the first model which describes tissue permeabilization by considering changes in tissue effective conductivity. Although the model presents the first approach toward description of permeabilization on tissue level and despite certain approximations (purely ohmic tissue conductivity) it shows good agreement with measurements.

$\sigma(E)$ dependency which is required by the model was determined by parameter estimation on experimental current results. The sigmoid shape of $\sigma(E)$ dependency shows that at lower E intensities smaller increase in conductivity is expected than at higher $\mathrm{E}$ intensities. Estimated $\mathrm{E}$ thresholds are: $460 \mathrm{~V} / \mathrm{cm}$ for reversible and $700 \mathrm{~V} / \mathrm{cm}$ for irreversible threshold. Obtained thresholds appear to be higher than the ones published in our previous work. The reason for difference is that previous values were determined on $\mathrm{E}$ distribution of nonpermeabilized tissue, thus, the increase in conductivity due to membrane permeabilization was not taken into account. As the new thresholds are higher also the calculated corresponding induced TMP is higher than previously published.

Based on the results of model validation two hypotheses arose aimed at explanation of the permeabilization process. First, fast dynamic changes of $E$ intensity during tissue permeabilization influence the change in tissue conductivity, however even if higher than irreversible threshold value they do not necessarily cause cell necrosis. Only when steady E intensities are present for a certain period of pulse length and if higher than irreversible threshold, they can cause cell necrosis. Model validation has, therefore, shown that $\sigma(E)$ dependency when combined with duration of exposure to $\mathrm{E}$ above irreversible threshold can give information about tissue necrosis.

Second, during permeabilization two transport mechanisms were observed: fast transport, i.e., ion transfer, which is reflected in the change of tissue conductivity and the slow transport, which indicates the transport of molecules (bleomycin ...). Both transports are presumably initiated at the same threshold value, however their dynamics is different. Due to the fact that ion transport is very fast, the consequent change in tissue conductivity causes further rapid changes in $\mathrm{E}$ distribution which propagates permeabilization. Final result is distribution of decreased $\mathrm{E}$ intensities across the permeabilized tissue than at the beginning of pulse application. The system behaves as if it had a specific negative feedback, which preserves cells from irreversible damage [26]. After this process is terminated it seems only the final steady E distribution that influences the origination of long lived stable pores, which enable the transport of molecules across cell membrane predominantly after the pulse by diffusion.

Based on the fact that model predicts the change in total current in accordance with measurements as well as it estimates the reversibly and irreversibly permeabilized volume, it can be used for the prediction of the volume of permeabilized tissue. Thus, validated sequential permeabilization model can be used for the simulation of permeabilization process. That is very important in clinics where electrode set-up and electrode parameters (amplitude only) can be estimated by simulation before the treatment in order to achieve effective permeabilization of a specific tissue volume. 
APPENDIX I

ON-Line MEASUREMENTS OF APPLIED Voltage AND CURRENT DURING THE FIRST PULSE
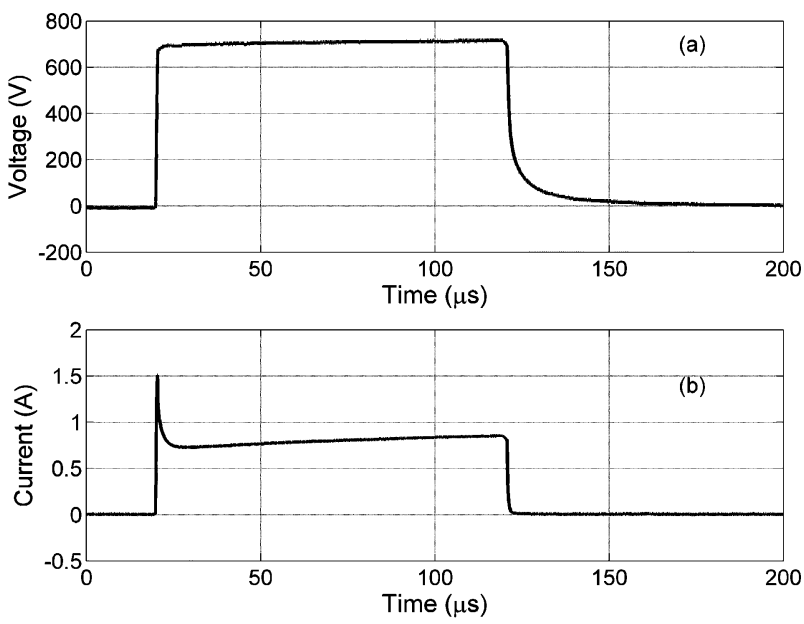

Fig. 11. (a) Voltage and (b) current during the first pulse.

\section{APPENDIX II}

Analytical Sequential Permeabilization Model of EleCtric Field Distribution BetweEn Two CONCENTRIC

\section{CYLINDRICAL ELECTRODES}

Electric field (E) distribution is calculated analytically for a simple tissue geometry, i.e. between two concentric cylindrical electrodes. The cross section of electrodes is shown in Fig. 12. Electric potential between the cylindrical electrodes satisfies the Laplace equation

$$
\Delta \varphi(r)=0 \text { or } \frac{1}{r} \frac{\partial}{\partial r}\left(r \frac{\partial \varphi}{\partial r}\right)=0 .
$$

The general solution is expressed as

$$
\varphi(r)=A \ln r+B .
$$

By taking into account boundary conditions on the electrodes and provided homogenous material we have

$$
\varphi(r)=\frac{u(t)}{\ln \left(\frac{R_{1}}{R_{0}}\right)} \ln \left(\frac{r}{R_{0}}\right)
$$

and

$$
\vec{E}=-\frac{u(t)}{\ln \left(\frac{R_{1}}{R_{0}}\right)} \frac{1}{r} \vec{e}_{r}
$$

where $\vec{e}_{r}$ is a unit vector. If reversible threshold value $\mathrm{E}_{0}$ is higher than $\mathrm{E}\left(\mathrm{R}_{0}\right)$ and lower than $\mathrm{E}\left(\mathrm{R}_{1}\right)$ the conductivity of the material where $\mathrm{E}>\mathrm{E}_{0}$ changes. Provided the conductivity changed to increased constant value $\sigma_{1}$ in the whole area where $\mathrm{E}>\mathrm{E}_{0}$, i.e., $\mathrm{r} \leq \mathrm{r}_{1}$ we get material with two different conductivities as shown in Fig. 12.

The potential is then described with

$$
\begin{array}{lll}
\varphi_{1}(r)=A \ln r+B & \text { for } \quad R_{0} \leq r \leq r_{1} \\
\varphi_{0}(r)=C \ln r+D & \text { for } \quad r_{1} \leq r \leq R_{1}
\end{array}
$$

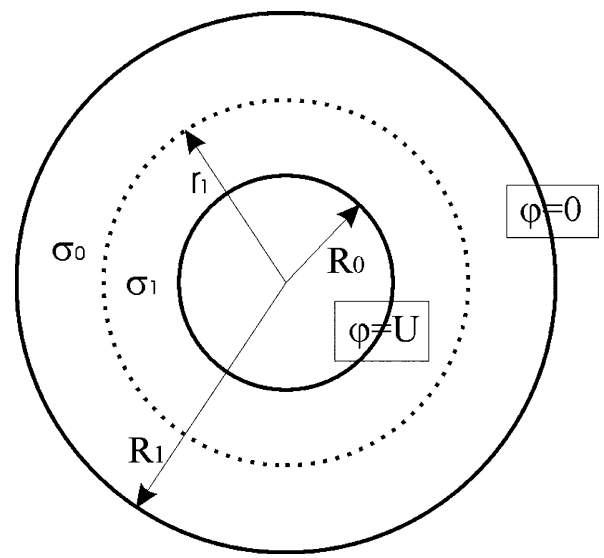

Fig. 12. Cross section of two concentric cylindrical electrodes. The area with increased conductivity is designated with $\mathbf{r}_{1}$.

By considering boundary conditions

$$
\begin{aligned}
& \varphi_{1}\left(R_{0}\right)=u(t), \quad \varphi_{0}\left(R_{1}\right)= 0, \quad \varphi_{1}\left(r_{1}\right)=\varphi_{0}\left(r_{1}\right), \\
& \sigma_{1} \frac{\partial \varphi_{1}\left(r_{1}\right)}{\partial r}=\sigma_{0} \frac{\partial \varphi_{0}\left(r_{1}\right)}{\partial r}
\end{aligned}
$$

following constants are calculated

$$
\begin{aligned}
& A=-\frac{u(t)}{\ln \left(\frac{r_{1}}{R_{0}}\right)+\frac{\sigma_{1}}{\sigma_{0}} \ln \left(\frac{R_{1}}{r_{1}}\right)} \\
& B=u(t)\left[1+\frac{\ln R_{0}}{\ln \left(\frac{r_{1}}{R_{0}}\right)+\frac{\sigma_{1}}{\sigma_{0}} \ln \left(\frac{R_{1}}{r_{1}}\right)}\right] \\
& C=-\frac{\sigma_{1}}{\sigma_{0}} \frac{u(t)}{\ln \left(\frac{r_{1}}{R_{0}}\right)+\frac{\sigma_{1}}{\sigma_{0}} \ln \left(\frac{R_{1}}{r_{1}}\right)}
\end{aligned}
$$

and

$$
D=\frac{\sigma_{1}}{\sigma_{0}} \frac{u(t) \ln R_{1}}{\ln \left(\frac{r_{1}}{R_{0}}\right)+\frac{\sigma_{1}}{\sigma_{0}} \ln \left(\frac{R_{1}}{r_{1}}\right)} .
$$

$\mathrm{E}$ in the area with nonpermeabilized tissue is than expressed as

$$
E(r)=-\frac{C}{r}=\frac{\sigma_{1}}{\sigma_{0}} \frac{u(t)}{\frac{\sigma_{1}}{\sigma_{0}} \ln \left(\frac{R_{1}}{r_{1}}\right)+\ln \left(\frac{r_{1}}{R_{0}}\right)} \frac{1}{r} \text { for } r_{1} \leq r \leq R_{1}
$$

and in the area with permeabilized tissue as:

$$
E(r)=-\frac{A}{r}=\frac{u(t)}{\frac{\sigma_{1}}{\sigma_{0}} \ln \left(\frac{R_{1}}{r_{1}}\right)+\ln \left(\frac{r_{1}}{R_{0}}\right)} \frac{1}{r} \text { for } R_{0} \leq r \leq r_{1} .
$$

\section{REFERENCES}

[1] E. Neumann, S. Kakorin, and K. Toensing, "Fundamentals of electroporative delivery of drugs and genes," Biochim. Biophys. Acta, vol. 48, pp. 3-16, 1999.

[2] J. C. Weaver and Y. A. Chizmadzhev, "Theory of electroporation: a review," Bioelectrochem. Bioenerg., vol. 41, pp. 135-160, 1996.

[3] R. Heller, M. Jaroszeski, J. Leo-Messina, R. Perrot, N. Van Voorhis, D. Reintgen, and R. Gilbert, "Treatment of B16 mouse melanoma with the combination of electropermeabilization and chemotherapy," Bioelectrochem. Bioenerg., vol. 36, pp. 83-87, 1995. 
[4] L. M. Mir, S. Orlowski, J. Belehradek Jr., J. Teissies, M. P. Rols, G. Serša, D. Miklavčič, R. Gilbert, and R. Heller, "Biomedical applications of electric pulses with special emphasis on antitumor electrochemotherapy," Bioelectrochem. Bioenerg., vol. 38, pp. 203-207, 1995.

[5] M. Jaroszeski, R. Gilbert, and R. Heller, "Electrochemotherapy: an emerging drug delivery method for the treatment of cancer," Adv. Drug Delivery Rev., vol. 26, pp. 185-197, 1997.

[6] L. M. Mir, "Therapeutic perspectives of in vivo cell electropermeabilization," Bioelechem., vol. 53, pp. 1-10, 2000.

[7] M. Čemažar, C. S. Parkins, D. J. Chaplin, G. M. Tozre, and G. Serša, "Electroporation of human microvascular endothelial cells: evidence for an anti vascular mechanism of electrochemotherapy," Br. J. Cancer, vol. 84, pp. 565-570, 2001.

[8] L. M. Mir, M. F. Bureau, J. Gehl, R. Rangara, D. Rouy, J. M. Caillaud, P. Delaere, D. Branellec, B. Schwartz, and D. Scherman, "High-efficiency gene transfer into skeletal muscle mediated by electric pulses," Proc. Nat. Acad. Sci., vol. 96, pp. 4262-4267, 1999.

[9] M. P. Rols, C. Delteil, M. Golzio, P. Dumond, S. Cros, and J. Teissie, "In vivo electrically mediated protein and gene transfer in murine melanoma," Nat. Biotechnol., vol. 16, pp. 168-171, 1998.

[10] H. Aihara and J. Miyazaki, "Gene transfer into muscle by electroporation in vivo," Nat. Biotechno., vol. 16, pp. 867-870, 1998.

[11] S. Satkauskas, M. F. Bureau, M. Puc, A. Mahfoudi, D. Scherman, D. Miklavčič, and L. M. Mir, "Mechanisms of in vivo DNA electrotransfer: respective contributions for cell electropermeabilization and DNA electrophoresis," Mol. Ther, vol. 5, pp. 1-8, 2002.

[12] D. Ferber, "Gene therapy: safer and virus-free?", Science, vol. 294, pp. $1638-1642,2001$.

[13] M. Puc, T. Kotnik, L. M. Mir, and D. Miklavčič, "Quantitative model of small molecules uptake after in vitro cell electropermeabilization," Bioelectrochemistry, vol. 60, pp. 1-10, 2003.

[14] L. M. Mir and S. Orlowski, "Mechanisms of electrochemotherapy," $A d v$. Drug Delivery Rev., vol. 35, pp. 107-118, 1999.

[15] B. Valič, M. Golzio, M. Pavlin, A. Schatz, C. Faurie, B. Gabriel, J. Teissie, M. P. Rols, and D. Miklavčič, "Effect of electric field induced transmembrane potential on spheroidal cells: theory and experiments," Eur. Biophys. J., vol. 32, pp. 519-528, 2003.

[16] M. Pavlin and D. Miklavčič, "Effective conductivity of a suspension of permeabilized cells: a theoretical analysis," Biophys. J., vol. 85, pp. 719-729, 2003.

[17] D. Miklavčič, K. Beravs, D. Šemrov, M. Čemažar, F. Demšar, and G. Serša, "The importance of electric field distribution for effective in vivo electroporation of tissues," Biophys. J., vol. 74, pp. 2152-2158, 1998.

[18] J. Gehl, T. H. Sorensen, K. Nielsen, P. Raskmark, S. L. Nielsen, T. Skorvsgaard, and L. M. Mir, "In vivo electroporation of skeletal muscle: threshold, efficacy and relation to electric field distribution," Biochim. Biophys. Acta, vol. 1428, pp. 233-240, 1999.

[19] K. Brandinsky and I. Daskalov, "Electrical field and current distributions in electrochemotherapy," Bioelectrochem. Bioenerg., vol. 48, pp. 201-208, 1999.

[20] R. A. Gilbert, M. J. Jaroszeski, and R. Heller, "Novel electrode designs for electrochemotherapy," Biochim. Biophys. Acta, vol. 1334, pp. 9-14, 1997.

[21] M. Puc, S. Čorović, K. Flisar, M. Petkovšek, J. Nastran, and D. Miklavčič, "Techniques of signal generation required for electropermeabilization. Survey of electropermeabilization devices," Bioelechem., vol. 64, pp. 113-124, 2004.

[22] D. Miklavčič, D. Šemrov, H. Mekid, and L. M. Mir, "A validated model of in vivo electric field distribution in tissue for electrochemotherapy and for DNA electrotransfer for gene therapy," Biochim. Biophys. Acta, vol. 1523 , pp. 73-83, 2000.

[23] G. A. Hofmann, S. B. Dev, S. Dimmer, and G. S. Nanda, "Electroporation therapy: a new approach for the treatment of head and neck cancer," IEEE Trans. Biomed. Eng, vol. 46, no. 6, pp. 752-759, Jun. 1999.

[24] J. Gehl and L. M. Mir, "Determination of optimal parameters for in vivo gene transfer by electroporation, using a rapid in vivo test for cell permeabilization," Biochem. Biophys. Res. Comm., vol. 261, pp. 377-380, 1999.

[25] S. B. Dev, D. Dhar, and W. Krassowska, "Electric field of a six-needle array electrode used in drug and DNA delivery in vivo: analytical versus numerical solution," IEEE Trans. Biomed. Eng., vol. 50, no. 11, pp. 1296-1300, Nov. 2003.

[26] I. G. Abidor, A. I. Barbul, D. V. Zhelev, I. N. Bandrina, E. M. Osipova, and S. I. Sukharev, "Electrical properties of cell pellets and cell electrofusion in a centrifuge," Biochim. Biophys. Acta, vol. 1152, pp. 207-218, 1993.
[27] M. Hibino, H. Itoh, and K. Kinosita Jr, "Time course of cell electroporation as revealed by submicrosecond imaging of transmembrane potential," Biophys. J., vol. 64, pp. 1789-1800, 1993.

[28] R. Davalos, B. Rubinsky, and D. M. Otten, "A feasibility study for electrical impedance tomography as a means to monitor tissue electroporation for molecular medicine," IEEE Trans. Biomed. Eng., vol. 49, no. 4, pp. 400-403, Apr. 2002.

[29] I. G. Abidor, L. H. Li, and S. W. Hui, "Studies of cell pellets II. Osmotic properties, electroporation and related phenomena: membrane interactions," Biophys. J., vol. 67, pp. 427-435, 1994.

[30] D. Šel, S. Mazeres, J. Teissie, and D. Miklavčič, "Finite element modeling of needle electrodes in tissue from the perspective of frequent model computation," IEEE Trans. Biomed. Eng., vol. 50, no. 11, pp. $1-12$, Nov. 2003.

[31] T. J. C. Faes, H. A. van der Meij, J. C. de Munck, and R. M. Heethaar, "The electric resistivity of human tissues $(100 \mathrm{~Hz}-10 \mathrm{MHz})$ a metaanalysis of review studies," Physiol. Meas., vol. 20, pp. R1-R10, 1999.

[32] L. A. Geddes and L. E. Baker, "Specific resistance of biological material-a compendium of data for the biomedical engineer and physiologist," Med. Biol. Eng., vol. 5, pp. 271-293, 1967.

[33] S. Rush, J. A. Abildskov, and R. McFee, "Resistivity of body tissue at low frequencies," Circ. Res., vol. XII, pp. 40-50, 1963.

[34] P. Schwan and C. F. Key, "The conductivity of living tissues," Ann. New York Acad. Sci., vol. 65, pp. 1007-1013, 1957.

[35] J. Teissie and M. P. Rols, "An experimental evaluation of the critical potential difference inducing cell membrane electropermeabilization," Biophys. J., vol. 65, pp. 409-413, 1993.

[36] E. Neumann and S. Kakorin, "Electrooptics of membrane electroporation and vesicles shape deformation," Curr. Opin. Colloid Interface Sci., vol. 1, pp. 790-799, 1996.

[37] D. J. Murray-Smith, "Advances in simulation model validation: theory, software and applications," in Proc. EUROSIM'95, 1995, pp. 75-84.

[38] F. A. Duck, Physical Properties of Tissue: A Comprehensive Reference Book. New York: Academic, 1990.

[39] D. C. Chang and T. S. Reese, "Changes in membrane structure induced by electroporation as revealed by rapid freezing electron microscopy," Biophys. J., vol. 58, pp. 1-12, 1990.

[40] S. J. Marrink, E. Lindahl, O. Edholm, and A. E. Mark, "Simulation of the spontaneous aggregation of phospolipids into bilayers," J. Am. Chem. Soc., vol. 123, pp. 8638-8639, 2001.

[41] H. Wolf, M. P. Rols, E. Boldt, E. Neumann, and J. Teissie, "Control by pulse parameters of electric field-mediated gene transfer in mammalian cells," Biophys. J., vol. 66, pp. 524-531, 1994.

[42] J. Teissie, N. Eynard, B. Gabriel, and M. P. Rols, "Electropermeabilization of cell membranes," Adv. Drug Delivery Rev., vol. 35, pp. 3-19, 1999.

[43] T. Y. Tsong, "Electroporation of cell membranes," Biophys. J., vol. 60, pp. 297-306, 1991.

[44] R. Susil, D. Šemrov, and D. Miklavčič, "Electric field induced transmembrane potential depends on cell density and organization," Electro. Magnetobiol., vol. 17, pp. 391-399, 1998.

[45] M. Pavlin, N. Pavšelj, and D. Miklavčič, "Dependence of induced transmembrane potential on cell density, arrangement, and cell position inside a cell system," IEEE Trans. Biomed. Eng., vol. 49, no. 6, pp. 605-612, Jun. 2002.

[46] K. Kinosita and T. Y. Tsong, "Formation and resealing of pores of controlled sizes in human erythrocyte membrane," Nature, vol. 268, pp. 438-441, 1977.

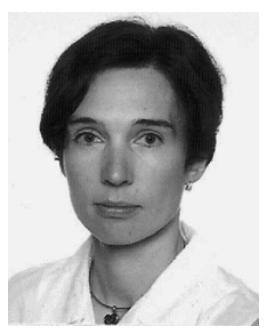

Davorka Šel was born in 1970. She received the M.Sc. and Ph.D. degrees in electrical engineering from the University of Ljubljana, Ljubljana, Slovenia.

Currently, she is Associate Researcher at the University of Ljubljana. Her main research interest is in the field of electroporation, numerical modeling of electric field distribution in tissue during electroporation and optimization of electroporation parameters. 


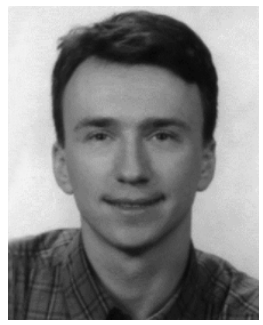

David Cukjati was born in 1970 in Ljubljana, Slovenia. He received the M.Sc. and Ph.D. degrees in electrical engineering at the University of Ljubljana, in 1998 and 2000, respectively.

$\mathrm{He}$ is presently a teaching assistant at the Faculty of Electrical Engineering, University of Ljubljana. He works in the field of biomedical engineering. His current research interests are electrical soft tissue healing and electroporation assisted drug delivery involving modeling, expert systems, and biomedical database and web applications design.

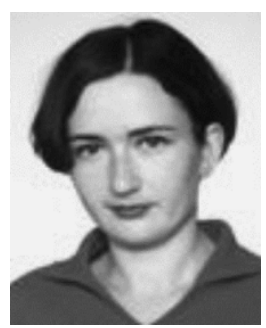

Danute Batiuskaite was born in 1971. She received the Ph.D. degree in biophysics field from the Vytautas Magnus University of Kaunas, Kaunas, Lithuania.

Currently, she is a Lecturer at the Vytautas Magnus University of Kaunas. Her main research interest is in the field of electroporation of cells and tissues, the search for the optimal electrochemoterapy conditions.

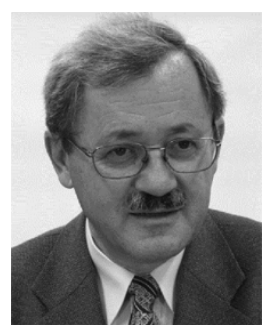

Tomaž Slivnik (M'72) received B.Sc., M.Sc., and the $\mathrm{Ph} . \mathrm{D}$. degrees in electrical engineering from University of Ljubljana, Slovenia, in 1971, 1973 and 1975, respectively, and the B.Sc. degree in mathematics in 1975.

He is currently a Professor on the Faculty of Electrical Engineering, University of Ljubljana. He has conducted research in numerical electromegnetics, microprocessor applications, AGV controls, and computer algorithms.

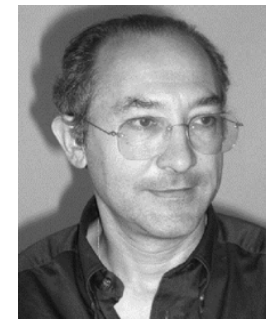

Lluis M. Mir was born in 1954 in Barcelona, Spain. He received the B.S. degree from University of Paris VI, Paris, France, in 1976, and the D.Sc. degree from the University of Toulouse, Toulouse, France, in 1983.

He is a fellow with Ecole Normale Supérieure de Paris, France. He is currently Director of Research of the CNRS at the CNRS UMR 8121 (Villejuif, France). His main interests lie in the fields of membrane electropermeabilization in vitro and in vivo, especially with regard to the transfer of antitumor drugs after tumor cells electroporation (electrochemotherapy) and to the electrotransfer of genes (electrogenetherapy) to healthy and malignant tissues.

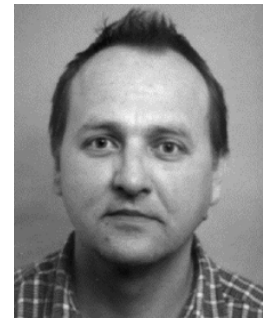

Damijan Miklavčič was born in 1963 in Ljubljana, Slovenia. He received the Ph.D. degrees in electrical engineering from the University of Ljubljana.

$\mathrm{He}$ is a Professor with the Faculty of Electrical Engineering and the Head of Laboratory of Biocybernetics, University of Ljubljana. He is active in the field of biomedical engineering. His interest in the last years focuses on electroporation assisted drug delivery, including cancer treatment by means of electrochemotherapy, tissue oxygenation, and modeling. 